\title{
Aktivisme Melampaui Laga: Perlawanan dan Gerakan Sosial Ultras di Freiburg
}

\author{
Aditya R. Pratama \\ Alumni Departemen Antropologi, Universitas Gadjah Mada \\ Email: apradityama21@gmail.com
}

\begin{abstract}
Corrillo Ultras and Supporter Crew SC Freiburg are football-supporters which are presented in the form of Ultras. In Germany itself, Ultras is a prominent scene of football supporter groups. Nevertheless, it is also well-known that there are a lot of stereotypes and stigma which are attached to the Ultras in general. From closely tied to communal violence and vandalism, to its association with right-wing ideology and Neo-Nazi movement. Conversely, Corrillo Ultras and Supporter Crew SC Freiburg had been organizing a various programs which focusing on issues of discrimination and racism. Some questions arise; why are Corrillo Ultras and Supporter Crew SC Freiburg actively involved in various social programs? How do they perceive the emerging social issues?
\end{abstract}

Keywords: Ultras, Germany, the Football Supporters, Social Movements, Counterculture

\begin{abstract}
Abstrak
Corrillo Ultras dan Supporter Crew SC Freiburg merupakan komunitas suporter sepakbola bergaya Ultras. Di Jerman sendiri, Ultras merupakan format yang populer. Beberapa stereotip dan stigma buruk masih melekat pada kelompok Ultras. Mulai dari suporter yang lekat dengan kekerasan dan vandalisme, hingga keterkaitannya dengan paham sayap kanan dan Neo-Nazi. Bertentangan dengan stereotip yang ada, Corrillo Ultras dan Supporter Crew SC Freiburg malah melakukan berbagai kegiatan sosial yang fokus kepada kritik terhadap perilaku diskriminatif dan rasisme. Muncul beberapa pertanyaan: mengapa Corrillo Ultras dan Suporter Crew SC Freiburg aktif terlibat dalam program sosial? Bagaimana dua kelompok Ultras di Freiburg mempersepsikan isu sosial yang sedang berkembang?
\end{abstract}

Kata Kunci: Ultras, Jerman, Suporter Sepakbola, Gerakan Sosial, Counter-culture 


\section{Pendahuluan}

Sepak bola adalah olahraga paling populer di Jerman. Dalam jurnal yang ditulis oleh Christian Brandt dan Fabian Hertel disebutkan bahwa jumlah penonton di liga utama Jerman, Bundesliga, mencapai 13 juta penonton tiap tahunnya sejak $2008(2015,66)$. Semaraknya sepak bola di Jerman dibuktikan juga dengan adanya lebih dari 30.000 klub yang tersebar dalam 13 strata piramida liga profesional, semi-profesional, dan amatir. Budaya menonton sepak bola di Jerman juga mendapat pengaruh dari Italia yang menyebarkan gagasan ultras sejak tahun 1990-an lalu. Jonas Gabler (dalam Brandt dan Hertel 2015, 66) bahkan menyebutkan setidaknya masing-masing klub di Jerman memiliki satu kelompok ultras hingga hari ini. Gabler menjelaskan ultras dalam sepak bola Jerman merujuk pada kesamaan etnisitas, kelompok orang yang mencintai satu klub saja, tak segan memberikan kritik pada klub jika sedang bermain buruk, atau juga terikat kuat dengan tradisi dan pahlawan lokal tempat suatu klub berdiri.

Dengan ciri-ciri yang ada, maka tak jarang ultras kerap memanifestasikan dukungannya pada klub dengan cara yang berlebih. Dukungan ultras bisa diidentifikasi di stadion lewat penggunaan kembang api dan flare (sebelum dilarang hampir di seluruh dunia), bendera besar, warna-warna mencolok, dan chants atau nyanyian bersama-sama yang menggema sepanjang pertandingan.

Meski secara umum kelompok ultras bersifat non-political (tidak mengacu pada pandangan politik), dalam berbagai kasus, ultras juga sering dikaitkan dengan gerakan politik tertentu -yang berkaitan atau tidak berkaitan sama sekali dengan sepak bola. Kelompok ultras yang demikian terikat kuat dengan identitas dan ideologi tertentu, seperti konservatisme atau hal-hal yang terkait tradisi, sosialisme, pandangan rasisme, dan juga nasionalisme atau bahkan anti-fasis. Tak jarang, kritik yang kerap disuarakan dalam stadion juga menyentuh aspek selain permainan dalam lapangan. Honigstein dalam The Guardian (2008) pernah membahas gerakan ultras Jerman yang membentangkan spanduk "Against Modern Football" sebagai bentuk kritik terhadap komersialisasi ${ }^{1}$ sepak bola, melambungnya harga tiket, dan aturan-aturan lain yang dianggap merugikan suporter. Selain itu, tumbuhnya Neo-Nazi juga kerap dikaitkan dengan kelompok ultras. Dalam artikel di Spiegel Online berjudul "Germany"s New Right: The Unholy Alliance of NeoNazis and Football Hooligans", tindak-tanduk kelompok ultras sering disorot melakukan diskriminasi terhadap pemain dengan latar belakang imigran dari Afrika dan Asia dan yang direpresentasi sebagai bagian dari gerakan Neo-Nazi atau ultra-nasionalisme di Jerman. Masing-masing kelompok ultras di Jerman memiliki pandangan yang saling berbeda.

Artikel ini akan membahas bagaimana corak dukungan kelompok ultras Jerman. Pada bagian awal, artikel ini akan membahas bagaimana peta ultras secara umum di Jerman yang pada kenyataannya lekat dengan politik aliran tertentu. Hal ini bisa dilihat

$1 \quad$ Komersialisasi sepak bola diidentikan dengan upaya monetisasi di dalam sepak bola. Hal ini berlangsung sebagai dampak dari industrialisasi terhadap sepak bola. Beberapa gejala yang bisa dilihat antara lain; naiknya harga tiket pertandingan, penjualan hak nama objek yang terkait dengan klub, melambungnya harga merchandise, dan lain-lain. Meski dipandang membantu keuangan klub, namun secara tidak langsung justru memberikan segmentasi kelas pada penonton. Alhasil, kelompok ultras yang lebih banyak lahir di kelas pekerja terancam tak bisa menikmati pertandingan di stadion. 
pada caranya mendukung di dalam maupun luar stadion. Selanjutnya, pembahasan akan berfokus pada ultras Freiburg untuk melihat kecenderungan posisinya dalam pemetaan kelompok ultras di Jerman. Ultras Freiburg yang secara khusus akan diteliti adalah Corrillo Ultras dan Supporter Crew SC Freiburg (Supporter Crew). Secara umum, dua kelompok ini menginisiasi gerakan yang berisi program-program sosial yang menolak rasisme dan menyasar kelompok pengungsi. Atas dasar inilah pertanyaan mengenai latar belakang dari keterlibatan ultras muncul: bagaimana Corrillo Ultras dan Supporter Crew SC turut berpartisipasi dalam gerakan sosial?

\section{Peta Ultras di Jerman}

Dalam pendahuluan disebutkan, secara umum kelompok ultras di Jerman tidak memiliki pandangan politik tertentu. Mereka kebanyakan fokus pada kegiatan mendukung tim dibanding mengurusi hal-hal di luar sepak bola. Pilz $(2006,46)$ mengungkapkan bahwa kelompok ultras di Jerman tidak begitu terkait dengan motif dan afiliasi politik apapun, bahkan beberapa cenderung apolitis. Tobias Wark (dalam Brandt dan Hertel 2015, 66) mengemukakan bahwa beberapa kelompok seperti Ultras Frankfurt (Eintracht Frankfurt), Ultras Nürnberg (1. FC Nürnberg), atau Commando Cannstatt (VfB Stuttgart) merupakan kelompok yang cenderung netral dalam politik. Netralitas yang dimaksud adalah suporter hanya akan mengedepankan isu dalam sepak bola, meski per individu memiliki pandangan politiknya masing-masing. Namun demikian, beberapa kelompok mendeklarasikan dirinya sebagai ultras beraliran sayap kiri (left-wing) atau kanan (right-wing). Aliran politik ini memengaruhi bentuk dukungan baik di dalam maupun luar stadion.

Ultras yang beraliran sayap kanan secara umum terciri lewat gerakan yang mengarah pada nasionalisme maupun identitas. Dalam catatannya di Fair Observer, Hans-Georg Betz menulis kebangkitan sayap kanan di sepak bola Jerman dipicu oleh munculnya sifat agresif penonton yang menyebar di banyak negara Eropa. Di bagian timur Jerman, ada Ultras Dynamo (SG Dynamo Dresden) yang memiliki citra negatif karena terkenal sering melanggar aturan terkait penggunaan kembang api. Mereka juga kerap melontarkan pandangan yang bernada rasisme dan anti-semit. Selain itu ada Ultras Chemnitz 99 (Chemnitzer FC) yang juga dikenal memiliki kekerabatan dekat dengan ekstrimis bawah tanah sayap-kanan.

Dalam divisi 3. Liga Jerman, ada klub semi-profesional yang bernama Türkgücü, sebuah klub yang merepresentasikan imigran asal Turki di Jerman. Bagi pendukung sayapkanan, Türkgücü merupakan sasaran kemarahan karena dianggap bukanlah klub Jerman dan seharusnya bermain di Liga Turki. Türkgücü sendiri berarti "kekuatan Turki", sesuatu yang tidak ingin dilihat oleh kelompok sayap-kanan.

Keberadaan imigran di Jerman paska Perang Dunia II dan krisis pengungsi Eropa tahun 2015 dilihat oleh kelompok sayap-kanan sebagai bentuk dari "Islamisasi" dan ancaman terorisme. Hal ini memicu beberapa kelompok sayap-kanan seperti Pegida dan partai politik seperti AfD (Alternative für Deutschland) melakukan kampanye dan protes atas kebijakan luar negeri Jerman yang membuka pintu selebar-lebarnya untuk pengungsi dan pencari suaka. Protes-protes ini tidak hanya dilakukan oleh Pegida dan AfD, namun juga dilakukan di dalam stadion oleh para kelompok suporter lain yang memiliki paham sayap kanan. 
Pendapat lain disampaikan oleh Alan Tomlinson dan Christopher Young yang mengungkapkan keberadaan paham politik sayap kanan pada lingkup suporter di Jerman $(2006,197)$. Pola-pola ini juga dapat dilihat ketika menelusuri pemberitaan media-media nasional di Jerman seperti Spiegel dan Deustche Welle. Spiegel sebagai media arus utama di Jerman dan Deustche Welle sebagai media milik pemerintah sering meliput berbagai pemberitaan mengenai kelompok ultras dengan afiliasi paham sayap kanan.

Spiegel Online 29 Agustus 2016, memberitakan kebijakan pemerintah kota Dortmund mengenai pemasangan kamera di dalam stadion untuk mengawasi dan mengidentifikasi suporter yang bertindak rasis. Langkah ini diambil oleh pemerintah kota setelah adanya korban kekerasan yang dilakukan oleh Borussenfront, sebuah kelompok ultras sayap kanan yang mendukung Borussia Dortmund. Borussenfront di Dortmund sendiri sudah dikenal sebagai fan scene dengan Neo-Nazi yang paling aktif di Jerman Barat. Artikel lain di Spiegel Online yang dipublikasikan tanggal 22 November 2012 memperlihatkan bahwa Süd Tribune di stadion Signal Iduna Park-yang diokupasi oleh kelompok ultras, beberapa kali kerap memperlihatkan spanduk dengan ornamen simbol-simbol Nazi. Artikel Spiegel tersebut juga memberitakan fan scene di Dortmund mendirikan sebuah organisasi Neo-Nazi yang bernama Autonomous Nationalists (AN), pemimpin organisasi menyebut dirinya sebagai "Führer" atau pemimpin dalam bahasa Jerman, yang erat kaitannya dengan Nazi Jerman.

Pada sisi yang lain, paham sayap-kiri juga berkembang dalam kelompok ultras di Jerman. Salah satu yang menonjol adalah Ultra Sankt Pauli (FC St. Pauli) yang berbasis di Hamburg. Sebagai suporter, mereka dianggap paling progresif karena mengusung aliran politik anti-fasis, anti homofobia, menjunjung tinggi kesetaraan. Mereka terkenal dengan logo tengkorak dan penggunaan ornamen punk di penjuru stadion. Faisal (2018) dalam Tirto.id menulis catatan Petra Daniel dan Christos Kassimeris yang melihat perkembangan ideologi politik di St. Pauli mencuat pada medio 1970-an ketika golongan kiri yang mendapat pendidikan politik mulai menyuarakan isu-isu soal imigran, anti-kapitalisme, anti-fasisme, dan anti-rasisme. Kampanye golongan kiri ini juga kemudian merembet ke stadion saat FC St. Pauli beraksi dan bertahan hingga millennium selanjutnya.

Klub paling sukses Jerman, Bayern Munich, juga memiliki kelompok ultras yang beraliran sayap-kiri bernama Schickeria. Disunting dari ESPN, Schickeria pada tahun 2014 memperoleh penghargaan Julius Hirsch Awards oleh federasi sepak bola Jerman. Penghargaan itu diberikan atas upaya Schickeria yang berkomitmen memerangi diskriminasi, xenofobia, anti-semit, dan rasisme. Kelompok ultras yang juga memiliki kampanye ramah terhadap pendatang adalah Corrillo Ultras dan Supporter Crew yang mendukung SC Freiburg. Dua kelompok terakhir akan menjadi topik bahasan dalam artikel ini.

Sosiolog asal Jerman, Gerd Dembrowski $(2012,59)$ melihat bahwa sepak bola Jerman semakin aktif mengampanyekan penolakan terhadap sepak bola modern yang memuja komersialisasi dan industrialisasi sepak bola. Dalam pengalamannya menonton sepak bola, ultras dianggap memiliki posisi kritik yang penting di masyarakat. Ia melihat bahwa penolakan terhadap industrialisasi sama halnya dengan melakukan penolakan terhadap polisi dan federasi sepakbola negara. Tak heran, di setiap laga sering terbentang spanduk bertuliskan "All Cops Are Bastard". Perlawanan terhadap negara ini terkait dengan kebijakan publik yang dianggap merugikan masyarakat kelas menengah ke bawah. Ramón Spaaij dan Carles Viñas $(2014,71)$ mengatakan bahwa gerakan sayap-kiri dalam kultur suporter tak 
lepas dari pengaruh skinhead ${ }^{2}$ yang mulai aktif dalam mendukung sebuah klub semenjak 1980-an. Kehadiran mereka menguat ketika terjadi transmisi pengetahuan dengan kelompok ekstrimis sayap-kiri. Tak heran beberapa kelompok ultras juga menggunakan simbol-simbol yang erat dengan subkultur skinhead.

\section{Ultras di Freiburg}

Secara geografis, Freiburg terletak di Jerman Barat Daya dan berbatasan langsung dengan Prancis dan Swiss. Kota Freiburg sendiri termasuk di dalam negara bagian BadenWurttemberg dan berpenduduk sekitar 218.000 jiwa dengan kepadatan penduduk sekitar 1.497 per kilometer persegi. Selain terkenal sebagai kota yang dipenuhi oleh pelajar dan mahasiswa, Freiburg juga terkenal sebagai kota yang paling cerah dan hangat di Jerman. Oleh karena iklimnya yang bersahabat tersebut, Freiburg turut menjadi rujukan wisata turis-turis lokal Jerman.

Posisi Freiburg yang strategis diantara perbatasan Perancis dan Swiss membuat kota ini turut diwarnai oleh imigran dari berbagai negara. Tak hanya dari negara-negara Eropa (Turki-sebagian berada di benua Asia dan sebagian di Eropa), namun juga imigran yang berasal dari Asia (Irak, Suriah, Tiongkok, Vietnam) serta Afrika (Somalia, Nigeria, Zimbabwe). Imigran-imigran tersebut sudah tinggal di Freiburg selama dua generasi sejak dekade 80-an. Imigran-imigran ini berintegrasi dan bekerja di berbagai sektor industri. Beberapa ada juga membuka restoran sendiri dan menjual makanan lokal dari negara asalnya, seperti imigran Turki yang menjual doner dan kebab, serta imigran Tiongkok dan Vietnam yang membuka restoran Asia dan Asia Markt (toko yang menjual barang-barang atau bahan makanan dari negara di Asia). Berdasarkan data yang dihimpun tahun 2010 dari United Nations Population Fund, tercatat bahwa Jerman memiliki jumlah imigran terbanyak ketiga di dunia yaitu sebanyak 9.550 .000 jiwa.

Dalam hal sepakbola, Freiburg juga memiliki budaya suporter yang kuat. Hal ini tidak dapat dipisahkan dari keberadaan klub sepakbola yang bermarkas di Freiburg, yaitu SC Freiburg. SC Freiburg yang berdiri tahun 1904 saat ini masih bermain di Bundesliga sejak promosinya di tahun 1990. Meskipun beberapa kali naik turun dari Bundesliga ke Bundesliga 2. SC Freiburg belum lama ini menorehkan prestasi dengan berlaga di UEFA Cup, sebuah kompetisi antarklub Eropa. SC Freiburg memiliki banyak suporter fanatik dan beberapa diantara mereka menegaskan diri sebagai ultras, antara lain: Corrillo Ultras, Immer wieder Freiburg (IWF), Natural Born Ultras (NBU) and Synthesia Ultras.

Salah dua kelompok suporter Freiburg yang akan dibahas jauh dari gambaran dari kelompok berpaham sayap kanan. Dua kelompok tersebut-adalah-Corrillo Ultras dan Supporter Crew SC Freiburg. Corrillo Ultras berdiri pada tahun 2013. Kelompok ultras ini sering menginisiasi gerakan-gerakan sosial yang menolak rasisme dan diskriminasi pada kelompok pengungsi. Seperti yang dicatat James Montague (2020), Corrillo Ultras pernah mendapatkan hibah sebesar 1.000 euro dari Fan Supporters Europe $e^{3}$ karena kegiatannya yang

2 Subkultur yang tumbuh di Inggris pada tahun 1960-an dan telah menyebar ke banyak negara. Pada awal perkembangannya skinhead adalah orang-orang kelas pekerja di Inggris yang aktif menyuarakan keadilan. Kini mereka sering diasosiasikan dengan rasisme dan Neo-Nazi karena menganggap lapangan pekerjaan banyak diisi oleh imigran.

3 Fan Supporters Europe adalah organisasi jaringan suporter akar rumput di 48 negara Eropa 
membantu pengungsi $(2020,214)$. Menurutnya, program seperti itu tak pernah dilakukan oleh kelompok ultras mana pun di dunia. Keberpihakan Corrillo pada isu-isu sosial bahkan secara tegas disampaikan dalam situs resminya, Corrillo.org, yang menyatakan:

"We want everyone to be able to watch a football match from their club. Priceless admission fees, stadium bans as punitive or so-called "preventive" measures, as well as racism, sexism, anti-Semitism, and homophobia, and every other form of discrimination oppose this idea and are fought by us in a wide variety of ways."

Agak berbeda dengan Corrillo Ultras, Supporter Crew sebenarnya didirikan sebagai forum besar pertemuan antara komunitas suporter SC Freiburg. Embrio Supporter Crew telah ada semenjak 2005 atas dasar kebutuhan mengorganisir kebutuhan bus angkutan untuk laga tandang. Kini, Supporter Crew telah banyak mengorganisasikan kegiatankegiatan fans yang berada di lingkaran SC Freiburg. Keanggotaan kelompok ini sangat terbuka terhadap komunitas suporter lain (termasuk dari Corrillo Ultras) dan individu yang mendukung tim dari Nordtribüne (tribun utara) Schwarzwald-Stadion. Dalam situs resminya ${ }^{4}$, Supporter Crew merupakan organisasi independen yang memiliki kepentingan untuk para fan. Mereka menyediakan forum bersama untuk memberikan info terkait keberangkatan suporter laga tandang SC Freiburg hingga masalah politik yang terjadi di kalangan fan. Tak heran, kegiatan Supporter Crew juga menyentuh isu-isu sosial gemanya di komunitas suporter akar rumput.

\section{Metode Penelitian}

Penelitian ini dilakukan pada bulan Juni 2015, di kota Freiburg, Jerman dalam rangka program Tridem Research yang diselenggarakan antara Universitas Gadjah Mada, Universitas Hasanuddin, dan Albert-Ludwigs Universitat. Metode yang digunakan di dalam penelitian ini adalah observasi partisipasi dan wawancara mendalam. Jalannya penelitian didampingi oleh dua partner mahasiswa Albert-Ludwigs Universitat.

Observasi partisipasi memungkinkan peneliti untuk bertemu, berbicara dan mengobservasi kegiatan informan di dalam konteks sehari-hari. Wawancara juga dilakukan dalam format narrative interview. Format ini memberi kesempatan kepada peneliti untuk mengajukan pertanyaan secara lebih eksploratif layaknya obrolan ringan namun tetap menyambut kemungkinan sudut pandang lain yang dikemukakan oleh informan, sebagaimana disebutkan oleh Judith Schlehe dalam artikelnya Qualitative Ethnographische Interviewformen (2008).

"Narrative interview is good to have a certain level of intimacy. Compared to the guideline interview this will give us the opportunity to get to know more about the way the group cooperates with each other and in the same way give the interviewed person the opportunity to speak freely and show their way of thinking about the subject. Also,

yang independen, representatif, dan demokratis. Organisasi ini bergerak pada isu-isu seputar sepak bola, seperti; urusan tiket, fan culture, diskriminasi dan kebijakan dalam sepak bola. Terarsip dalam https://www.fanseurope.org/en/about-fse/history-a-mission.html diakses pada 2 November 2021.

4 Terarsip dalam https://supporterscrew.de/die-scfr/ diakses pada 2 November 2021. 
our questions will be spontaneous which gives the interview another kind of dynamic" (Schlehe 2008, 126).

Di dalam penelitian ini, beberapa tantangan sempat dijumpai. Penelitian berlangsung di saat Bundesliga musim 2014/15 baru saja berakhir. Tak ada laga yang dapat ditonton maupun momen-momen bersama yang dapat diobservasi. Partisipasi observasi hanya bisa dilakukan di beberapa kegiatan seperti rapat, nongkrong di bar. Tak ayal, siasat dan fleksibilitas diperlukan. Beberapa kegiatan sosial Ultras yang mayoritas berlangsung di 2014 didapatkan melalui dokumentasi kegiatan, foto, video dokumenter maupun liputan-liputan dari media massa lokal. Hal serupa juga terjadi pada kegiatan wawancara. Keterbatasan waktu penelitian membuat jawaban dari beberapa pertanyaan wawancara masih belum tergali secara maksimal. Oleh karena itu, setelah kembali dari Freiburg beberapa wawancara dengan informan masih tetap berlanjut melalui korespondensi surel dan telepon video (Skype).

Berkembangnya cakupan penelitian antropologi dari small society ke complex society seperti masyarakat urban memang membuat peneliti kesulitan untuk menjalin hubungan dengan informan dengan insentif dan jangka waktu yang cukup lama. Hal ini, menurut Eriksen (2008) dapat diimbangi dengan merelasikan data empiris dengan data statistik, acuan historis, maupun media massa secara lebih selektif. Cara tersebut dimungkinkan selama peneliti tidak terjebak defragmentasi dan dekontekstualisasi data.

\section{Budaya Tanding sebagai Alternatif}

Guna memahami keterlibatan ultras di Freiburg di dalam program-program sosial, konsep budaya tanding atau counter-culture dikemukakan oleh Keith A. Roberts (1978) dalam artikelnya "Towards a Generic Concept of Counter-Culture". Dijelaskan bahwa budaya tanding perlu dipahami sebagai gejala penolakan yang eksplisit di dalam suatu kebudayaan dominan yang sedang berubah. Dorongan akan adanya penolakan menurut Roberts $(1978,20)$ dapat disebabkan oleh adanya cita-cita dan ketertarikan kelompok untuk membuat masyarakat menjadi lebih baik. Alih-alih menggunakan kekerasan dan perubahan secara politis, budaya tanding lebih berusaha untuk menawarkan alternatif yang mampu mempengaruhi masyarakat dominan untuk mengikuti gerakan secara sukarela. Ia merancang pilihan kultural di mana masyarakat dominan mau untuk "melihat pencerahan" dan mengadopsi gaya hidup yang lebih "humanis".

Perlu diperhatikan juga bagaimana suatu perlawanan bisa disebut sebagai budaya tanding, sebagai keberagaman dari sebuah ekspresi kebudayaan atau malah sebagai salah satu bentuk penyimpangan. Dalam hal ini Roberts mengajukan beberapa indikator dari budaya tanding, yaitu intra-cultural phenomenon atau tumbuhnya kelompok budaya tanding dari matriks kebudayaan dominan itu sendiri. Sebagaimana disebutkan oleh Roberts bahwa budaya tanding merupakan upaya untuk menentang budayanya sendiri (culture heretics) yang mencoba untuk menempa kebudayaan alternatif, alih-alih sebagai pendatang atau "alien" yang berusaha untuk merekonstruksi tradisi lamanya. Roberts membahas fenomena cultural heretics dengan contoh pendatang yang menempati negara baru dan tidak memiliki rasa cinta pada kebudayaan baru di negara tujuan. Para komunitas pendatang ini kemudian berusaha melestarikan budaya dari asal mereka. Namun, benturan- 
benturan budaya menyebabkan para imigran harus mau berkompromi dengan budaya baru demi kelangsungan hidup. Maka, terjadilah asimilasi antara dua budaya yang kadang dianggap menyimpang dari arus budaya utama (heretic/ bidah).

Roberts juga berpendapat bahwa suatu peristiwa sosial disebut budaya tanding apabila keberadaannya melanggar batas dari central values atau nilai utama dari sebuah kebudayaan dan memiliki ketidakcocokan besar antara kultur utama dengan budaya tanding. Dari argumen Roberts diatas, terlihat bahwa keberadaan central values merupakan kausalitas utama dari kemunculan counter-culture.

Dalam konteks kelompok ultras atau masyarakat suporter secara umum, penyimpangan bisa diidentifikasi dari perilaku ultras yang tidak sama dengan citra umum yang seringnya negatif. Di sisi lain, perlu diperhatikan pula sistem sosial manakah yang menjadi sasaran budaya tanding yang dilakukan oleh kelompok ultras di Freiburg. Kemudian, perlu diperhatikan apakah penolakan nilai-nilai dalam masyarakat yang dominan di Freiburg atau ketidaksetujuan mereka semata menyasar kepada kebudayaan yang dibangun oleh komunitas ultras secara global (mengingat sejarah perkembangan ultras sebagai gaya suporter yang mengglobal). Dalam hal ini mungkin ada baiknya untuk memahami pengertian kebudayaan di dalam konteks globalisasi yang diajukan oleh Arjun Appadurai.

Menurut Arjun Appadurai dalam Modernity at Large: Cultural Dimensions of Globalization $(1996,147)$, globalisasi telah banyak mempengaruhi kehidupan modern. Derasnya arus migrasi dan media massa global membuat manusia mengalami suatu deteritorialisasi atau suatu keadaan di mana orang-orang tak lagi terikat dengan konteks geografis. Ia berpendapat bahwa masyarakat di dunia saat ini terhubung secara imajiner melalui gelombang sosial global atau "global social flow" berupa teknologi, politik, media, identitas, dan keuangan. Melalui berbagai kepentingan inilah, manusia kemudian mengimajinasikan dirinya di dalam komunitas dan struktur sosial yang tidak bergantung pada keberadaan fisik. Berbagai praktek sosial yang dibangun oleh masyarakat saat ini merupakan buah dari imajinasi sosial global.

Dalam melihat kebudayaan dalam konteks globalisasi, Appadurai menolak pandangan yang melihat kebudayaan sebagai sesuatu yang statis, terbatas secara spasial, dan tidak disadari secara historis. Ia berargumen bahwa kebudayaan adalah kemampuan masyarakat yang dengan sadar mampu mengartikulasikan identitas kelompoknya dan membentuk set perbedaan dengan kelompok yang lain di dalam skala trans-nasional maupun global. Hal yang kemudian ia sebut sebagai culturalism. Secara singkat, konsep dari Appadurai ini membantu peneliti untuk melihat kecenderungan suporter di Freiburg yang melakukan perlawanan identifikasi negatif ultras secara global.

\section{Corrillo Ultras dan Supporter Crew SC Freiburg}

Corrillo Ultras adalah kelompok Ultras pertama yang saya temui di Freiburg. Corrillo merupakan kelompok Ultras dengan jumlah anggota yang tergolong besar, setidaknya ada sekitar 60 orang bergabung dengan Corrillo. Sebagai Ultras, Corrillo merupakan kelompok Ultras yang sangat baru, ia didirikan pada tahun 2013. Berdirinya Corrillo sendiri didasari oleh kebutuhan anggotanya akan suatu kelompok, mengingat Ultras yang cukup besar sebelumnya yaitu Wild Jugend Freiburg atau WJF telah bubar. Di sisi lain, terbentuknya 
Corrillo turut didorong oleh kegelisahan para pendiri untuk membuat kelompok yang lebih aktif dan tak sekedar "mengonsumsi" pertandingan.

Jared adalah salah satu informan yang merupakan salah satu anggota pendiri Corrillo Ultras. Saat ditemui, Jared berpenampilan sederhana, mengenakan kaos berwarna abu-abu, topi, celana jeans, dan sepatu olahraga. Ia mengaku telah menjadi suporter sejak 1995 ketika pertama kali diajak oleh orang tuanya menonton pertandingan akhir pekan. Menurut Jared pribadi, menjadi Ultras sendiri berarti "lebih" daripada menjadi suporter biasa. Ia merasa wajib untuk datang ke setiap pertandingan, bernyanyi, bersorak-sorai, melakukan koreografi, serta menaruh banyak perhatian terhadap regulasi dan politik terkait sepakbola.

Anggota-anggota Corrillo seluruhnya terdiri dari laki-laki dengan latar belakang yang beragam, mulai dari mahasiswa, pekerja industri, karyawan, dan pengrajin. Nama Corrillo sendiri diperoleh dari bahasa Spanyol yang berarti "lingkaran", yang diinspirasi dari gerak melingkar bersama-sama yang dibuat oleh tim sepakbola sebelum kick-off pertandingan dimulai. Ritual melingkar tersebut melambangkan motivasi dan kohesi sosial sehingga para anggota pendiri Corrillo sepakat untuk menamai kelompoknya berdasarkan konsep tersebut.

Sebagai kelompok Ultras, Corrillo tidak memiliki pemimpin dan struktur organisasi yang formal. Rencana kegiatan dan pembagian kerja dirancang dan diatur dengan egaliter. Beberapa pembagian kerja tersebut diantaranya, mengorganisir transportasi dan tiket untuk laga tandang, serta mengurus situs internet. Meskipun demikian, Corrillo Ultras selalu memiliki agenda untuk rapat rutin tiap bulannya dengan membahas isu-isu tertentu.

Struktur organisasi yang terbuka ini juga terlihat melalui syarat-syarat yang perlu dilakukan untuk memasuki Corrillo Ultras. Jared mengungkapkan ada setidaknya 30 anggota inti yang terdiri dari pendiri dan pihak-pihak yang bergabung dengan Corrillo di awal pembentukanya. 30 anggota inti ini memiliki hak untuk menentukan dapat atau tidaknya seorang calon anggota menjadi bagian dari Corrillo Ultras. Beberapa syaratsyarat tersebut diantaranya ialah datang ke setiap laga SC Freiburg, membangun hubungan persahabatan yang loyal dengan sesama anggota Corrillo, menyetujui nilai-nilai di dalam Corrillo, serta wajib mengerti apa itu dan bagaimana menjadi seorang Ultras.

Apabila dilihat dari komposisi anggotanya, Corrillo memiliki rentang usia yang tidak terlalu jauh. Mayoritas dari mereka berasal dari usia muda sekitar 20 hingga 35 tahun. Kendati demikian, Corrillo tidak membatasi persyaratan umur apabila ada calon anggota yang hendak bergabung. Corrillo lebih mengedepankan adanya perasaan tanggung jawab tertentu untuk hadir di setiap pertandingan SC Freiburg sebagai syarat untuk bergabung dengan kelompok.

Selain Jared, saya berkesempatan untuk mewawancarai anggota Corrillo lainnya bernama Victor. Dibandingkan dengan Jared, Victor jauh lebih muda. Ia berusia 21 tahun dan baru menyelesaikan studinya di Freiburg dan saat ini bekerja sebagai editor foto di salah satu majalah fans berjudul 11Freunde. Kendati ia lahir di kota lain, namun Victor dan keluarganya pindah dan tinggal di Freiburg semenjak ia berusia 2 tahun. Ia selalu merasa bahwa ia "berasal" dari Freiburg.

Pertemuan Victor dengan komunitas suporter bola sudah dimulai sejak ia berusia 15 tahun. Di kontak pertamanya, ia merasa beruntung karena sudah menemui orang-orang yang saat ini tergabung dengan Corrillo Ultras. Sebagaimana Jared, Victor juga merupakan salah satu anggota pendiri Corrillo Ultras. Menurut Victor, Corrillo Ultras berbeda dengan 
kelompok suporter lain di Freiburg. Ia menganggap bahwa apa yang dilakukan oleh Corrillo cenderung lebih politis, hal itu terwujud melalui kritik Corrillo terhadap harga tiket, kebijakan klub, dan cara mendukung. Tak hanya itu, Corrillo juga kritis terhadap isu-isu yang berkembang di luar seperti isu pengungsi dan migran.

Nilai-nilai loyalitas dan relasi pertemanan yang diusung Corrillo mau tak mau membuat beberapa anggota Corrillo harus mengorbankan relasi sosial lainya. Meskipun ada yang aktif di saat hari pertandingan saja, namun ada juga yang hampir selalu menghabiskan waktu bersama Corrillo. Sebagaimana Victor, yang mengungkapkan bahwa ia menghabiskan waktu setiap menitnya bersama Corrillo. Selain bekerja sebagai fotografer, menggambar dan bermain terompet sebagai hobinya, hampir tidak ada waktu tersisa untuk teman-teman kuliahnya. Ia pun merasa tidak menginginkan hubungan pertemanan lain di luar Corrillo Ultras.

Salah satu ciri khas yang banyak ditemui dalam kelompok Ultras adalah koreografi raksasa di tribun penonton. Namun, tidak setiap pertandingan koreografi bisa ditemukan di bagian Nordtribüne, kandang dari Corrillo. Corrillo Ultras secara khusus hanya menampilkan koreografi pada laga-laga kandang yang dianggap signifikan. Laga yang dianggap penting ini antara lain laga pembuka Bundesliga, pertandingan besar atau pertandingan melawan klub-klub dengan predikat juara, penghuni klasemen papan atas dan Baden-Derby yaitu pertandingan melawan klub dari satu daerah yang sama seperti VfB Stuttgart dan Karlsruher SC. Selain laga-laga penting, Corrillo Ultras hanya menyanyikan yel-yel, menggelar spanduk dan mengibarkan bendera-bendera. Pengecualian terjadi ketika ada pertandingan bersejarah, seperti peringatan 110 tahun SC Freiburg, atau peringatan 60 tahun Schwarzwald Stadion. Dalam hal ini, Corrillo Ultras dan kelompok Ultras di Nordtribüne akan mempertontonkan koreografi yang sangat besar, tanpa memperdulikan klub mana yang dihadapi.

Adanya konsepsi penting atau tidaknya suatu laga dalam menampilkan koreografi dilatarbelakangi oleh tingginya biaya untuk membeli perlengkapan yang dibutuhkan untuk mengorganisir sebuah koreografi. Dalam laga SC Freiburg melawan Borussia Monchengladbach tanggal 10 Agustus 2016 lalu, setidaknya 3.014 euro habis untuk membeli perlengkapan dan peralatan yang dibutuhkan. Dalam pertandingan tersebut Corrillo berhasil mengumpulkan 3.287 euro selama tiga bulan dan menghabiskan 821 euro untuk kertas berwarna, 788 euro untuk kawat, 376 euro untuk cat, 270 euro untuk bendera, 254 euro untuk bahan perekat, 200 euro untuk kain, 130 euro untuk tali, 74 euro untuk kuas dan roller, 61 euro untuk flyer, 15 euro untuk gunting, 9 euro untuk pengait, 16 euro untuk biaya pengangkutan dan masih tersisa 273 euro untuk dana kas. Informasiinformasi tersebut kemudian dicetak di selebaran oleh Corrillo sebagai bentuk transparansi dan pertanggungjawaban kepada sesama penyumbang.

Untuk mencukupi kebutuhan perlengkapan ini, Corrillo mengumpulkan dana baik melalui penggalangan dana langsung di stadion, maupun di situs internet mereka. Sebelum pertandingan biasanya ada dua orang berdiri di depan pintu Nordtribüne. Mereka menenteng kotak kardus dan penonton lain bisa menyumbang secara sukarela. Corrillo Ultras juga melakukan penggalangan dana melalui berjualan stiker lewat situs internet mereka.

Saat mulai berproses membuat koreografi, ada beberapa lokasi yang dipakai Corrillo Ultras. Beberapa kali berlangsung di stadion, di rumah salah satu anggota, maupun di 
kantor Fanprojekt ${ }^{5}$. Koreografi yang ditampilkan pun berbeda-beda setiap pertandingan, tergantung pada isu yang ingin diangkat. Dalam merancang koreografi, Corrillo Ultras paling tidak memerlukan waktu satu hingga dua minggu sebelum pertandingan. Koreografi biasanya dirancang oleh anggota Corrillo secara bersama-sama; apabila ada salah satu orang memiliki ide atau konsep tertentu, maka di dalam forum anggota Corrillo lainnya akan menambahkan maupun menyempurnakannya dengan ide-ide lain.

Pada hari pertandingan, ada satu peraturan yang wajib dipegang; yaitu bahwa seluruh penonton yang hadir di Nordtribüne wajib membantu dan berpartisipasi dalam menggelar koreografi. Tak peduli ia bagian dari Ultras atau bukan. Meski peraturan ini tidak tertulis, namun nilai ini senantiasa dipatuhi oleh penonton dan kelompok Ultras di Nordtribüne. Sebuah teguran atau tindakan pengusiran dari Nordtribüne akan dilakukan apabila ada salah satu individu yang enggan atau menolak untuk berpartisipasi, Sanksi lainnya yakni jika ada kelompok lain yang hendak membuat koreografi maka sebagai gantinya ia tidak akan dibantu oleh kelompok ultras di Nordtribüne. Namun demikian, hal tersebut sangat jarang terjadi. Individu atau kelompok yang duduk menonton di Nordtribüne biasanya sudah sadar dan mengenal peraturan-peraturan tak tertulis ini.

Untuk menggelar koreografi, Corrillo turut bekerjasama dengan pihak klub yang diwakili oleh Die Fangemeinschaft atau paguyuban fans. Kerjasama tersebut lebih menyangkut urusan teknis seperti pemasangan kawat di langit-langit Nordtribüne untuk mengangkat spanduk pada koreografi, pengorganisasian waktu kapan koreografi ditampilkan dan kapan pemain mulai masuk ke dalam lapangan, dan lain-lain. Pada kasus SC Freiburg, koreografi selalu ditampilkan sesaat sebelum kick-off pertandingan dimulai layaknya sambutan kepada kedua tim yang akan bermain. Di dalam Nordtribüne, seluruh kelompok ultras maupun individu berperan untuk mengangkat kertas berwarna, sebagian kecil lainnya mengangkat spanduk raksasa. Pada koreografi, orang-orang yang bertugas mengangkat kertas ini wajib menggerakkan tangannya sesuai perintah capo tifosi (pemimpin kelompok ultras), entah sebatas bergerak ke kiri dan kanan secara bersamasama, atas ke bawah, maupun sekedar menggoyangkannya seperti gelombang yang harmoni. Dalam 15 menit, koreografi berjalan, seluruh Nordtribüne akan terselimuti warna merah, putih dan kadangkala hitam sebagai warna yang menjadi identitas klub SC Freiburg Di samping Corrillo, ada pula Supporter Crew SC Freiburg (atau selanjutnya dapat disebut dengan Supporter Crew). Layaknya Corrillo, Supporter Crew merupakan kelompok yang sangat aktif. Mereka tak hanya mendukung di Nordtribüne namun juga di setiap laga tandang. Supporter Crew sendiri berdiri sejak tahun 2005. Dilatarbelakangi oleh kebutuhan untuk mengorganisir bus bersama-sama menuju laga tandang. Mengingat ketiadaan kelompok ultras di Schwarzwald Stadion setelah Wild Jugend Freiburg (WJF) bubar pada tahun 2003.

Sedikit berbeda dengan Corrillo Ultras yang mementingkan nilai-nilai loyalitas dan

$5 \quad$ Fanprojekt adalah organisasi non-profit yang dilatarbelakangi oleh kegelisahan akan generasi muda yang rentan terlibat dalam aksi kekerasan, mengingat kelompok umur ini masih berada di dalam tahap eksplorasi diri. Sebagaimana dikutip dalam websitenya Fanprojekt memiliki visi utama untuk mencegah suporter muda yang berusia dibawah 18 tahun untuk melakukan kekerasan serta menghindarkan mereka dari pengaruh alkohol, rokok, dan narkoba. Fanprojekt diinisasi oleh DFB (Deustchland Fussball-Bund), asosiasi sepak bola Jerman. 
pertemanan untuk masuk ke dalam kelompok. Supporter Crew sebenarnya bisa dimaknai sebagai forum besar pertemuan antar suporter yang biasa menempati Nordtribüne. Supporter Crew merupakan organisasi formal independen yang memiliki kepentingan terkait dengan SC Freiburg. Di mana anggota yang ingin menjadi bagian dari kelompok perlu mengisi formulir pendaftaran serta membayar biaya keanggotaan sekitar 15 euro setiap enam bulannya. Keanggotaannya sendiri pun berasal dari kelompok komunitas suporter SC Freiburg yang lain, kelompok ultras, atau individu. Dari keanggotaan dengan Supporter Crew, beberapa hak istimewa yang bisa didapat antara lain adalah potongan harga tiket bus dan tiket masuk di dalam laga-laga tandang, atribut-atribut Supporter Crew dan SC Freiburg, serta keikutsertaan di dalam aksi-aksi suporter seperti pembuatan flyer, spanduk, dan koreografi. Anggota Supporter Crew yang saat ini tercatat adalah sekitar 250 orang.

Struktur organisasi Supporter Crew lebih tegas dibanding Corrillo. Anggota-anggota Supporter Crew dipimpin oleh 8 orang dewan yang berhak mengambil keputusan untuk kelompok. Dewan ini disebut sebagai Presidium, dan orang-orang yang berhak duduk di Presidium dipilih di dalam rapat anggota tahunan. Keputusan-keputusan yang dibuat oleh antara lain seperti seberapa banyak anggaran yang hendak digunakan untuk membuat koreografi, berapa banyak bus yang ingin digunakan untuk transportasi menuju laga tandang, pemesanan tiket untuk laga tandang, perencanaan dalam membuat selebaran, spanduk maupun koreografi. Di samping pengambilan keputusan yang bersifat teknis tersebut, Presidium juga berperan untuk berbicara dengan pihak-pihak luar seperti polisi atau media ketika ada kasus-kasus hukum yang menimpa anggota Supporter Crew.

Apabila dilihat struktur organisasinya, Supporter Crew lebih bersifat luwes dan tidak terlalu mengikat anggotanya karena latar belakang anggota yang telah bergabung dengan komunitas lain. Satu-satunya nilai dan tujuan yang diutamakan adalah mendukung klub SC Freiburg. Sehingga di dalam kegiatan-kegiatan kelompok, Supporter Crew lebih menekankan pada aspek dukungan sepakbola saja seperti pengorganisasian pertandingan tandang, aksi koreografi, pembuatan spanduk dan selebaran. Di luar kegiatan utama tersebut, seperti di dalam program sosial atau donasi, Supporter Crew berpartisipasi secara resmi sebagai kelompok, namun tidak mewajibkan seluruh anggotanya untuk bergabung. Meskipun terdapat beberapa perbedaan, mayoritas anggota kedua ultras-Corrillo Ultras dan Supporter Crew-mengungkapkan bahwa perkenalannya dengan fan scene sudah dimulai sejak kanak-kanak. Pada perkembangannya, mereka kemudian bergabung menjadi anggota ultras dan diwajibkan untuk memahami nilai-nilai menjadi seorang ultras serta menjadi bagian di dalam lingkaran pertemanan. Melalui proses tersebut mereka terlibat dan mengimajinasikan diri menjadi bagian di dalamnya. Imajinasi dan artikulasi identitas mereka di dalam fan scene nampak melalui identifikasi siapa yang mereka sebut teman, siapa lingkungan terdekat mereka, dan aktivitas-aktivitas mereka.

Melalui hasil wawancara terlihat bahwa anggota-anggota ultras membatasi dan membedakan lingkungan pergaulannya di dalam ultras dan di lingkungan sesama suporter sepakbola. Hal ini-merujuk kepada pengertian culturalism dari Appadurai $(1996,31)$ bahwa mereka mengimajinasikan struktur perasaan tertentu sehingga menjadi praktik sosial yang terorganisir, dalam hal ini menyaksikan dan menikmati sepakbola, serta menjadi pendukung klub. Aktivitas ini kemudian menghasilkan bentuk-bentuk material tertentu lokalitas yang dinamakan sebagai fan scene. 


\section{Aktiv-fans sebagai Counter-culture}

Ketidaksetujuan akan bentuk-bentuk diskriminasi dan rasisme direspons oleh kelompok ultras di Nordtribüne dengan berbagai bentuk. Corrillo Ultras, yang baru dibentuk pada tahun 2013 lalu melawan segala bentuk diskriminasi dan rasisme di dalam sepakbola melalui koreografi, program donasi, serta beberapa kampanye simbolis. Jared mengungkapkan bahwa di awal pembentukannya, Corrillo memang tak ingin sekedar mendukung klub SC Freiburg sebagaimana terjadi di kelompok ultras sebelumnya. Namun Corrillo ingin menjadi kelompok ultras yang aktif dan bersahabat, mereka menyebutnya sebagai "Aktiv-fans". Dalam wawancara bersama Jared, aktiv-fans merujuk pada aktivitas kelompok yang menolak diskriminasi dan terlibat dalam pembentukan masyarakat yang lebih humanis.

"Tentu saja kami punya, yang pertama ialah mendukung klub, namun kami juga
memiliki tujuan lain yaitu menjadi suporter yang bersahabat dan aktif di dalam fan
scene, kami mencoba untuk mencoba membunyikan isu di dalam fan scene seperti
melawan diskriminasi misalnya, segala hal yang tidak kami lakukan di dalam
kelompok lama" (Jared, wawancara 06/15).

Corrillo Ultras dan Supporter Crew secara konsisten menyampaikan kampanyenya dengan menggunakan koreografi, pengibaran bendera dan spanduk-spanduk serta melalui diskusi dan sosial media. Salah satu koreografi yang secara gamblang menyatakan diri sebagai bentuk penolakan terhadap diskriminasi dan rasisme adalah koreografi "FIFA Abolish Racism Fights" yang dikibarkan pada laga melawan Frankfurt bulan Agustus 2016 lalu. Melalui koreografi tersebut, Corrillo Ultras dan Supporter Crew hendak mengkritik FIFA atau asosiasi sepakbola dunia yang melakukan pembiaran ketika banyak kasus diskriminasi dan rasisme terjadi. Mulai dari masih banyaknya cemoohan dan ejekan bernada rasisme yang masih mendominasi Bundesliga, 83 kasus rasisme di liga Rusia, hingga kejadian penyerangan yang dilakukan oleh kelompok sayap kanan di Aachen, Jerman.

Kepedulian akan pengungsi juga disampaikan melalui pembentangan spanduk "Refugees Welcome, Bild Nicht" saat pertandingan SC Freiburg melawan FSV Mainz 19 November 2016 lalu. Pembentangan spanduk ini merupakan bentuk pemboikotan terhadap majalah Bild yang dianggap melakukan pencitraan dalam membela pengungsi. Padahal diketahui, Bild merupakan majalah yang berafiliasi dengan paham sayap-kanan. Melalui spanduk tersebut Corrillo Ultras dan Supporter Crew berusaha menyampaikan ketidaksetujuannya dengan majalah tersebut yang tidak pernah melakukan apa-apa untuk pengungsi selain membuat emblem dan hashtag "Wir Hilfen" ("Kami Membantu") di sosial media.

Kelompok ultras di Freiburg memang kental dengan asosiasi sayap-kiri dan banyak melawan gejala-gejala diskriminasi yang dilakukan oleh politisi sayap-kanan. Dalam artikel Felix Tamsut di DW, pada pertengahan 2020 lalu, Corrillo memenangkan tuntutan hukum yang dilayangkan oleh politisi sayap kanan dari AfD, Dubravko Mandic. Masalah bermula ketika Corrillo Ultras membentangkan spanduk yang mengaitkan Mandic dengan "Nazi" saat ia menonton pertandingan pembuka musim 2019/2020. Mandic yang keberatan kemudian mengajukan laporan resmi pada pihak kepolisian. Setelah berbulan-bulan kejaksaan memutuskan untuk menutup kasus karena spanduk tersebut dianggap sebagai 
bagian dari kebebasan berpendapat. Paska keputusan, Corrillo memberikan pernyataan resmi, "Bagi kami, ini menunjukkan bagaimana berurusan dengan Nazi."

Di kasus yang lain, kelompok-kelompok ultras Freiburg terkenal memiliki ketertarikan dengan isu sosial dan politik, baik di dalam stadion maupun isu perkotaan. Anggota-anggota ultras sering terlibat dalam demonstrasi melawan aktivitas sayap-kanan. Di dalam stadion, mereka juga sering melawan seksisme dan homofobia dalam sepak bola.

Dalam rangka menjadi aktiv-fans, isu pengungsi turut menjadi fokus utama Corrillo Ultras. Mengingat masih banyak perlakuan diskriminasi dan rasisme yang dihadapi oleh pengungsi maupun imigran yang mayoritas datang dari Timur Tengah dan Afrika Utara. Di sisi lain, isu pengungsi merupakan isu yang sedang hangat di Jerman. Keadaan sosial dan finansial anggota Corrillo Ultras yang lebih beruntung dibandingkan para pengungsi, serta adanya komitmen kelompok untuk menolak segala bentuk diskriminasi dan rasisme, membuat Corrillo memutuskan untuk membantu pengungsi-pengungsi yang ada di Freiburg.

Isu pengungsi juga menjadi perhatian dari beberapa anggota Supporter Crew. Hal ini terutama disuarakan oleh Antonia, salah satu informan. Ia merasa bahwa pihak-pihak yang mendiskriminasi pengungsi hanya mendengar kabar dari berita-berita di surat kabar saja. Diperlukan suatu momen pertemuan langsung antara diskriminan dengan para pengungsi, sehingga cara pandang mereka mengenai pengungsi bisa berubah. Sepak bola, menurut Antonia adalah topik yang mampu menyatukan dan mencairkan sekaligus, sehingga sebaiknya perlawanan terhadap diskriminasi perlu berangkat dari sepak bola itu sendiri. Melalui sepak bola, para pengungsi yang dianggap sebagai orang asing bisa berinteraksi dengan mudah dengan warga lokal, tanpa perlu pendekatan khusus, tanpa belajar bahasa, dan sebagainya. Sehingga mereka yang pada awalnya melihat pengungsi sebagai "sekedar pengungsi" menjadi pengungsi yang merupakan sesama "manusia". Potensi ini setidaknya menjadi salah satu latar belakang diselenggarakannya program-program sosial yang bertemakan sepak bola. Salah satu contohnya adalah penyelenggaraan turnamen sepak bola "Tatort Stadion" yang bertujuan untuk mempertemukan orang-orang dengan berlatar belakang berbeda, seperti pengungsi, kelompok suporter, ultras, dan lain sebagainya.

Selain menyuarakan gagasan mereka melalui spanduk dan koreografi. Corrillo Ultras dan Supporter Crew juga berpartisipasi di dalam program-program sosial yang diselenggarakan bersama pihak luar. Program sosial yang pertama ialah "Secondfanshirt", sebuah program donasi yang diinisiasi oleh FSE (Football Supporter Europe) dilatarbelakangi oleh keprihatinan akan krisis pengungsi yang diakibatkan oleh perang di Timur Tengah dan Ukraina. Dalam jaringan suporter sepak bola seluruh Eropa ini, FSE mengundang seluruh kelompok suporter di Jerman untuk bergabung. Hal ini disambut baik oleh Corrillo Ultras dan Supporter Crew bersama 24 kelompok suporter lainnya di seluruh Jerman. Gagasan di dalam program ini adalah menyumbangkan kaos sepak bola bekas (secondhand shirt), serta berbagai atribut sepak bola lainnya seperti syal. Sumbangan tersebut kemudian dijual ke eBay, sebuah situs jual-beli online. Uang dari hasil penjualan kemudian disumbangkan untuk lembaga swadaya masyarakat atau organisasi nonpemerintahan yang memiliki fokus untuk membantu para pengungsi.

Dalam melaksanakan program ini, Corrillo dan Supporter Crew mengumpulkan kaos sepak bola bekas selama musim Bundesliga berjalan. Mereka membuka stan di beberapa pertandingan kandang, di mana anggota ultras, kelompok suporter lain dan 
penonton biasa bisa langsung mendonasikannya di stan tersebut. Lokasi yang dipilih ialah di dekat infostand di bawah Nordtribüne, serta di depan pintu masuk Nordtribüne dan Sud Tribune. Selain di stadion, Corrillo dan Supporter Crew juga menempatkan boksboks di beberapa tempat yang strategis seperti toko souvenir di Schwarzwald Stadion, toko olahraga di Oberlinden, serta di kantor Fanprojekt. Meskipun pada perencanaannya hanya kaos sepak bola bekas yang disumbangkan. Corrillo Ultras dan Supporter Crew, juga berinisiatif mendonasikan baju-baju dan pakaian olahraga terbaru. Dalam hal ini, mereka menyumbangkannya langsung ke kamp pengungsi terdekat. Antonia pribadi merasa bahwa pengungsi juga membutuhkan baju-baju baru, utamanya untuk kebutuhan olahraga seperti kaos atau jogging suit.

Apabila diartikan secara harfiah di dalam bahasa Indonesia, "Tatort Stadion" berarti "Stadion Tempat Kejadian Perkara”. Ide “Tatort Stadion" sejatinya datang dari Fanprojekt, sebuah organisasi non-profit yang memiliki fokus terhadap pendampingan suporter muda. Sebelum diselenggarakan di Freiburg, program ini sebenarnya sudah diselenggarakan di kota-kota Jerman lainnya di mana Fanprojekt berada. Kendati inisiatif "Tatort Stadion" dimulai oleh Fanprojekt namun kedua kelompok ultras di Freiburg, yaitu Corrillo Ultras dan Supporter Crew juga berperan signifikan dalam desain program tersebut.

Secara garis besar, "Tatort Stadion" merupakan program kampanye menolak adanya diskriminasi, rasisme, seksisme, dan homofobia di dalam sepak bola. Program ini diselenggarakan di Volkhoschule Freiburg pada tanggal 10-21 Maret 2015 dan sudah menginjak edisi kedua. "Tatort Stadion" terdiri dari beberapa susunan acara, salah satu yang utama ialah pameran foto dan atribut-atribut yang berkaitan dengan sepak bola dan fan scene. Atribut-atribut ini mulai dari syal dari klub-klub sepakbola di Jerman, badge yang bergambarkan logo kelompok ultras, kaos klub sepak bola, serta spanduk-spanduk bekas yang digunakan oleh kelompok suporter saat melakukan aksi di dalam stadion.

Di dalam pameran tersebut, terpampang spanduk besar yang mencuri perhatian. bertuliskan "Fusball ist Alles Auch Schwuz" yang dalam bahasa Indonesia berarti "sepak bola adalah segalanya, pun halnya dengan gay", "Rassismus ist ein Arschloch!" yang berarti "rasisme adalah omong kosong", serta tak lupa "Football for Equality" yang berarti "sepak bola untuk kesetaraan". Spanduk-spanduk ini merupakan beberapa spanduk yang digunakan oleh Corrillo Ultras dalam melakukan aksi dukungan di dalam pertandingan SC Freiburg. Selain berperan dalam penyediaan properti pameran, Corrillo Ultras juga membantu Fanprojekt di dalam penyediaan dana. Salah satunya dengan menjual kaos yang bertuliskan "Fight against discrimination". Dana yang dihasilkan dari penjualan kaos ini digunakan untuk membiayai berbagai acara dalam "Tatort Stadion".

Selain berpartisipasi dalam pameran. Antonia dan Phillip juga terlibat di dalam salah satu susunan acara bertajuk "Antirassismustag", sebuah acara kampanye anti-rasisme yang ditujukan untuk remaja usia 13 hingga 15 tahun yang berlokasi di ruang pers dan ruang VIP Schwarzwald Stadion. Dalam "Antirassismustag", Antonia dan Phillip mengajak beberapa siswa-siswa sekolah dan sebuah kamp pengungsi di Freiburg untuk berdiskusi mengenai rasisme dan diskriminasi melalui sudut pandang suporter sepak bola; seperti bagaimana rasanya menjadi kelompok ultras, bagaimana rasanya melihat rasisme dan diskriminasi di dalam stadion, selain itu isu migrasi juga tidak luput untuk dibahas. Di penghujung acara, "Antirassismustag" diakhiri dengan membuat spanduk bersama-sama yang bertuliskan "Fusball gegen rassismus" atau yang berarti "sepak bola menolak rasisme". 
Melalui narasi-narasi di atas, terlihat bagaimana pola perlawanan terhadap diskriminasi dan rasisme yang dilakukan oleh Corrillo Ultras dan Supporter Crew. Kedua kelompok tersebut tidak menggunakan cara-cara kekerasan maupun konfrontasi fisik. Alih-alih, mereka mengajak masyarakat untuk lebih peka terhadap isu-isu diskriminasi dan rasisme melalui berbagai aksi di dalam Nordtribüne dan berbagai kegiatan sosial di luar lapangan. Hal ini terwujud melalui visi yang diusung oleh mereka, yaitu menjadi aktiv-fans. Seperti yang dikatakan oleh Keith A.Roberts dalam Towards a Generic Concept of CounterCulture (1979) bahwa counter-culture merancang pilihan kultural supaya masyarakat mau "melihat pencerahan" dan juga mengadopsi gaya hidup alternatif.

Perlu digarisbawahi pula bahwa sasaran budaya tanding yang dilawan Corrillo Ultras dan Supporter Crew bukanlah bukanlah budaya dominan Freiburg yang sudah terbuka dan multikultural, melainkan kulturalisme yang hadir di dalam sepak bola dan budaya suporter di Jerman (Appadurai, 1996: 13). Apabila dilihat dengan visinya sebagai aktivfans, Corrillo Ultras dan Supporter Crew dapat dikategorikan sebagai gerakan sosial yang defensif mengingat kedua kelompok ultras tersebut merupakan bagian dari masyarakat Freiburg yang tidak menginginkan pula akan adanya diskriminasi dan rasisme. Pada kasus ini, Corrillo Ultras dan Supporter Crew mengimajinasikan dirinya di dalam komunitas dan struktur sosial fan scene yang tidak tergantung pada keberadaan fisik (Appadurai 1996,4). Hal ini terungkap sebagaimana disebutkan dalam bab sebelumnya, bahwa arah gerakan kedua kelompok ini bertujuan untuk memberi penyadaran kepada fan scene.

\section{Epilog}

Meski secara garis besar pertumbuhan ultras bersifat non-political, tidak dipungkiri dinamika sosio-kultur di Jerman juga turut membentuk kelompok yang kemudian mengafiliasi pada pandangan politik tertentu. Gelombang migrasi paska Perang Dunia II dan krisis pengungsi Eropa tahun 2015 dilihat oleh kelompok sayap-kanan sebagai bentuk dari "Islamisasi" dan ancaman terorisme. Gejala ini turut memengaruhi kelompok ultras dalam mengaktualisasikan dukungannya dalam sepak bola. Alhasil, muncul banyak suara diskriminatif dan rasis di tengah aktivitas sepak bola. Beberapa kelompok ultras menginisiasi dan mengorganisasi protes terhadap kehadiran pengungsi dan imigran, bahkan ada juga yang menggelar kampanye anti-Islam atau anti-pendatang di kota-kota di Jerman. Namun demikian, hal tersebut berbanding terbalik dengan apa yang ditemui di kota Freiburg.

Dua kelompok suporter di Freiburg yang cenderung beraliran politik sayap-kiri, yaitu Corrillo Ultras dan Supporter Crew SC Freiburg sepakat untuk terlibat di dalam program-program sosial yang memiliki fokus untuk melawan diskriminasi dan rasisme di dalam fan scene atau lingkup suporter. Berangkat dari masalah ini, kedua suporter mengidentifikasi diri sebagai "Aktiv-fans"; sebuah visi sebagai kelompok ultras untuk menjadi lebih bersahabat dan aktif di dalam isu sosial-politik. Visi ini terwujud dalam berbagai kegiatan sosial, mulai dari program donasi dan kampanye.

Melalui hasil observasi partisipasi dan wawancara mendalam diketahui bahwa anggota-anggota Corrillo Ultras dan Supporter Crew SC Freiburg memiliki kegelisahan yang sama. Keduanya mengeluhkan akan makin maraknya diskriminasi dan rasisme di dalam fan scene yang menjadi kultur atau lokalitas mereka. Di sisi lain, sentimen-sentimen 
ini makin menunjukkan pola yang sama dengan bangkitnya Nazi paska Perang Dunia I.

Hal ini kemudian mendorong dua kelompok ultras di Freiburg untuk melakukan counter-culture atau sebuah budaya tanding. Perlawanan ini bukan melalui jalan politik maupun kekerasan, namun lebih kepada memberikan penyadaran dan alternatif lain kepada masyarakat. Pun demikian dengan sasaran perlawanan yang dituju, tidak menyasar kepada kebudayaan Freiburg yang dominan. Secara eksplisit, Corrillo Ultras dan Supporter Crew mengangkat isu kampanyenya kepada fan scene yang menjadi kultur ultras. Nilai-nilai masyarakat Freiburg yang multikultural dan terbuka memperlihatkan bahwa kedua ultras ini secara defensif, menolak berbagai pengaruh sayap kanan yang datang dari luar dengan mencanangkan visi "Aktiv-fans" dan program sosial miliknya. Pada banyak kesempatan, Corrillo dan Supporter Crew banyak mengagendakan kegiatan yang menolak rasisme, diskriminasi, homofobia, dan lain-lain. Hal ini menjadi kecenderungan baru dalam dunia ultras di mana pada aras global lebih banyak terikat dengan gerakan-gerakan sayap-kanan yang diskriminatif terhadap pendatang dan imigran.

\section{Referensi}

Appadurai, A. 1996. Modernity at Large: Cultural Dimensions of Globalization. Minneapolis London: University of Minnesota Press.

Betz, H-G. 2020. “German Football for the 'Real' Germans”. Diakses pada Rabu, 18 Agustus 2021. Pukul 15.10 WIB. https://www.fairobserver.com/region/europe/hans-georgbetz-germany-football-racism-far-right-fans-bundesliga-turkgucu-munchennews-15250/

Brandt, C. dan Fabian, H. 2015. 'German Ultras as Political Players? An Analysis of The Protest Against 'The Secure Stadium Experience'. Miscellanea Anthropologica et Sociologica 16(4):64-82 DOI: 10.5604/20842937.1189813

Bundesliga. 2016. "SC Freiburg Spielen Gegen Abstieg Staerkt Zusammenhalt Bundesliga". Diakses pada Kamis 8 September 2016, Pukul 20.38 WIB. http://www.fussballgegennazis.de/beitrag/scfreiburg_spielen_gegen_abstieg_staerkt_zusammenhalt_ bundesliga.03/15.

Chilli. 2016. "Monster Sehen Anders Aus Die Freiburger Ultras”. Diakses pada Kamis 8 September 2016, Pukul 20.40 WIB. http://chilli-freiburg.de/02-freiburg/monstersehen-anders-ausdie-freiburger-ultras

Corrillo. 2019. “About Us”. Diakses pada Selasa, 2 November 2021. Pukul 01.45 WIB. https:// corrillo.org/ueber-uns/.

Corrillo Ultras. 2019. "Einzigartier Sport Club Freiburg E.V”. Diakses pada Selasa,6 September 2016. Pukul 15.30 WIB. https://corrillo.org/.

Eriksen, T. H. 2004. What is Anthropology?. Oslo: University of Oslo Press.

ESPN. 2014. "Bayern Munich ultra group given award for Kurt Landauer work". Diakses pada Rabu, Diakses pada 18 Agustus 2021. Pukul 13.00 WIB. https://www.espn.com/ soccer/league-name/story/2089485/headline.

Faisal, M. 2018. St. Pauli, Klub Sepakbola Musuh Sejati Kaum Fasis. Diakses pada Rabu, 18 Agustus 2021. https://tirto.id/st-pauli-klub-sepakbola-musuh-sejati-kaum-fasis-cJAU

Fanprojekt Freiburg. "Fanprojekt Freiburg". Diakses pada Selasa, 6 September 2016. Pukul 16.11 WIB. http://www.fanprojekt-freiburg.de/ 
FSE. 2008. Background \& History. Diakses pada Selasa, 2 November 2021. Pukul 02.00 WIB. https://www.fanseurope.org/en/about-fse/history-a-mission.html

Honigstein. R. 2008. "Are German fans really turning against the beautiful game?”. Diakses pada Rabu, 18 Agustus 2021. Pukul 13.00 WIB. https://www.theguardian.com/ football/2008/apr/07/europeanfootball.sport2

Honigstein, R. 2012. "Ultras Play with Fires as Bundesliga enfulged by Flares and Violence". Diakses pada Kamis 8 September 2016, Pukul 20.41 WIB. http://www.theguardian. $\mathrm{com} /$ football/blog/2012/nov/26/bundesliga-flares-violence-safety-measures.

Montague, J. 2020. 1312: Among the Ultras: A Journey With the World's Most Extreme Fans. London: Penguin Books.

Pilz, Gunter. (2006); "Tatort Stadion“: Jugendliche Fankulturen und die Inszenierung Von Gewalt. Hannover: Leibniz Universitat Hannover.

Roberts, K. A. 1998. “Towards A Generic Concept of Counter-Culture”, Sociological Focus Vol. 11, No. 2, 1978. https://www.jstor.org/stable/20831076. Diakses pada 5 Agustus 2016.

SCFR.2021.“The SCFR”.Diakses pada Selasa, 2 November 2021. Pukul 01.55 WIB, https:// supporterscrew.de/die-scfr/.

Schlehe, J. 2008. “Qualitative Ethnograpische Interviewformen”, dalam Beer, Bettina: Methodern ethnologischer Feldforschung. Berlin: Reimer.

Spaaij, R. dan Carles V. 2014. "Political Ideology and Activism in Football Fan Culture in Spain: A View From The Far Left” dalam Peter Kennedy dan David Kennedy (ed.) Fan Culture in European Football and the Influence of Left Wing Ideology. London: Routledge.

Spiegel. 2012. "Dortmund Goes High Tech: Football Clubs Nabs Neo-Nazi with Help of New Camera”. Diakses pada Selasa, 6 September 2016. Pukul 15.44 WIB. http://www. spiegel.de/international/germany/football-club-borussia-dortmund-goes-high-techto-combat-neo-nazis-a-852733.html

Spiegel. 2014. "Germany"s New Right: The Unholy Alliance of Neo-Nazis and Football Hooligans”. Diakses pada Selasa, 6 September 2016. Pukul 16.05 WIB. http://www. spiegel.de/international/germany/new-right-wing-alliance-of-neo-nazis-andhooligans-appears-ingermany-a-1000953.html

Tamsut, F. 2020. 'SC Freiburg ultras win legal battle after labelling far-right politican 'Nazi'. Diakses pada Selasa, 2 November 2021. Pukul 06.42 WIB.https://www.dw.com/en/scfreiburg-ultras-win-legal-battle-after-labeling-far-right-politician-nazi/a-54732771.

Tomlinson, A dan Young, C. 2006. German Football: History, Culture, Society. London: Routledge.

Wikipedia. 2017. Freiburg im Breisgau. Diakses pada Minggu 8 Januari 2017. Pukul 08.05 WIB. https://en.wikipedia.org/wiki/Freiburg_im_Breisgau\#Government. 